\title{
Assessment of Cardiac Performance by First Pass Radionuclide Angiocardiography in Infants and Ghildren with Normal Heart and Endocardial Fibroelastosis
}

\author{
Tomoharu Akiba, Masaru Yoshikawa, Masahiko \\ Kinoda, Shinsuke Otaki, Yokio Kobayashi and Tetsuo \\ SATO \\ Department of Pediatrics, Yamagata University School of \\ Medicine, Yamagata 990-23
}

\begin{abstract}
Akiba, T., Yoshikawa, M., Kinoda, M., Otaki, S., Kobayashi, Y. and Sato, T. Assessment of Cardiac Performance by First Pass Radionuclide Angiocardiography in Infants and Children with Normal Heart and Endocardial Fibroelastosis. Tohoku J. exp. Med., 1986, 148 (1), 15-23 — Peak to peak time from the right and to the left ventricle (PPT), left ventricular ejection fraction, left ventricular peak ejection rate and left ventricular peak filling rate were measured by first pass radionuclide angiocardiography in 27 infants and children with normal heart and in 8 patients (18 studies) with endocardial fibroelastosis. In normal subjects, the PPT significantly correlated with heart rate $(r=-0.87, p<0.001)$. A PPT corrected by the heart rate (cPPT) was calculated by rotation of the regression equation relating the variables: $\mathrm{cPPT}=\mathrm{PPT}+0.018 \times($ heart rate $)-2.1$. The cPPT averaged $3.0 \pm 0.0$ (mean \pm S.E.) sec. Consequently, there was no significant correlation between the $\mathrm{PPT}$ and heart rate, but the $\mathrm{cPT}$ and body surface area are significantly correlated $(r=0.41, p<0.05)$. Left ventricular ejection fraction, peak ejection rate and peak filling rate averaged $68 \pm 2 \%, 4.2 \pm 0.3 / \mathrm{sec}$ and $4.8 \pm$ $0.3 / \mathrm{sec}$, all of which were independent of the heart rate and body surface area. In patients with endocardial fibroelastosis, the cPPT was prolonged $(4.7 \pm 0.4 \mathrm{sec})$, and left ventricular ejection fraction, peak ejection rate and peak filling rate were all reduced $(28 \pm 4 \%, 1.7 \pm 0.2 / \mathrm{sec}$ and $1.8 \pm 0.2 / \mathrm{sec})$. These results indicate that parameters obtained from the radionuclide angiocardiography are useful for evaluating cardiac performance in patients with endocardial fibroelastosis. _ first pass radionuclide angiocardiography ; cardiac performance ; normal values; endocardial fibroelastosis
\end{abstract}

Cardiac catheterization and contrast ventriculography have been traditionally required for an analysis of cardiac performance in infants and children. Because of the invasive nature of these procedures, however, the indication of them has been limited to selected groups of patients. The introduction of noninvasive radionuclide angiocardiography permitted the assessment of cardiac 
performance widely in pediatric age group. Nevertheless, studies on normal values for cardiac performance derived from the radionuclide angiocardiography in infants and children are scarce until now. The purpose of this study, therefore, is to present normal values for peak to peak time from the right to left ventricle (PPT), left ventricular ejection fraction, peak ejection rate and peak filling rate in infants and children by first pass radionuclide angiocardiography and to evaluate the clinical significance of these parameters on assessing cardiac performance in patients with endocardial fibroelastosis.

\section{Materials and Methods}

\section{Patients}

Thirty-five infants and children were studied; 27 patients ( 17 boys and 10 girls) with Kawasaki disease who showed normal coronary arteries in selective coronary arteriograms, and 8 patients ( 5 boys and 3 girls) with endocardial fibroelastosis who revealed dilatated left ventricular chambers in cineventriculograms. The patients data in these 35 cases are summarized in Tables 1 and 2. A body surface area was calculated using the formula described by Haycock et al. (1978).

\section{Radionuclide techniques}

Data acquisition was performed with a gamma camera (Ohio-Nuclear $\Sigma 410 \mathrm{~S}$ ) equipped with a slant hole collimator and the data were stored on a computer system (DEC, PDP-11/ $34,128 \mathrm{kB}$ ). The patient was placed in a $30^{\circ}$ right anterior oblique or in a modified $45^{\circ}$ left anterior oblique position. A teflon venous sheath of 22 or 24 gauge was inserted in a cubital vein, and 10 to $20 \mathrm{mCi}$ of ${ }^{99} \mathrm{~m} \mathrm{Tc}$-pertechnetate was given as a bolus injection followed by 5 to $10 \mathrm{ml}$ of saline solution. Precordial activity was recorded during the first circulation through the heart. Data were accumulated at 20 to 30 msec intervals and the whole process was completed within 10 to $15 \mathrm{sec}$. These data were collected in frame mode using 20 frames/sec and a $64 \times 64$-pixel matrix.

After the data acquisition, the time activity curves were generated from the regions of interest on the right and left ventricles. Then, the tracer flow curves were obtained with smoothing the right and left ventricular original curves, and PPT was defined as the time interval between the peaks of these two tracer flow curves. The value of the original time activity curve of the left ventricle was divided by the tracer flow curve, and corrected time activity curve was obtained. The peaks and valleys of the curve corresponded to the end-diastolic and end-systolic points respectively, which were adopted as the time reference points for synchronization (Komatani et al. 1981). The frames of five or more cardiac cycles were superimposed in synchronization with the cardiac phase using the both points of end-diastole and end-systole for construction of a closed-loop movie format. In order to identify the region of interest of the left ventricle, mitral and aortic valve planes were first traced with a joy stick system. Then, the edge-detection within noncardiac structure was performed using the isocount line of $50 \%$ of the maximum intraventricular counts on the end-diastolic frame. In order to correct the interference by radioactivity of noncardiac structure, the regions of interest for background subtruction were assigned as semiannular rings which surround the left ventricle on the end-diastolic frame avoiding radioactivity of the aorta and left atrium.

In this manner, left ventricular time-volume curve and first derivative $(\mathrm{dV} / \mathrm{dt})$ curve were obtained simultaneously. The following three indices were determined by computer analysis of these two curves: (1) ejection fraction $(\%)=($ end-diastolic counts-end-systolic counts) $\times 100 /$ (end-diastolic counts-background counts), (2) peak ejection rate $(/ \mathrm{sec})=\mathrm{a}$ maximum value of negative $\mathrm{dV} / \mathrm{dt}$ during systole in $\mathrm{dV} / \mathrm{dt}$ curve, (3) peak filling rate 


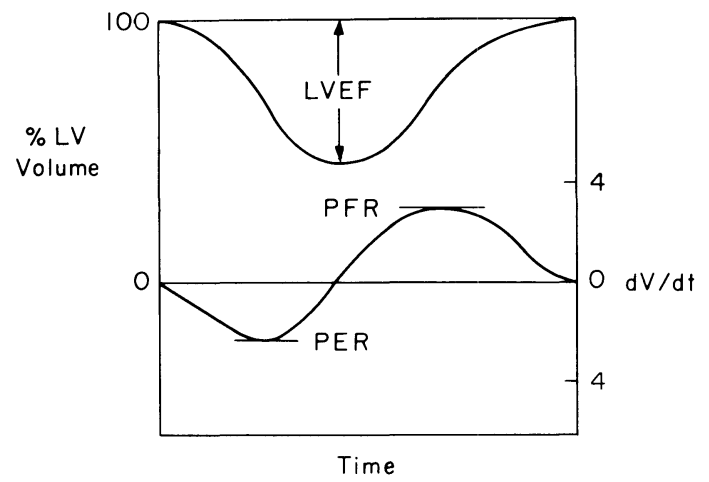

Fig. 1. Left ventricular volume curve (upper) and first derivative curve (lower). $\mathrm{EF}$, ejection fraction; PER, peak ejection rate; PFR, peak filling rate.

$(/ \mathrm{sec})=$ a maximum value of positive $\mathrm{dV} / \mathrm{dt}$ during diastole in $\mathrm{dV} / \mathrm{dt}$ curve (Fig. 1$)$.

\section{Statistical analysis}

The data was presented as mean \pm standard error of the mean. Statistical analysis was performed with the Student $t$ test. The level of statistical significance was $p<0.05$.

\section{REsUlts}

In normal subjects, the PPT averaged $3.1 \pm 0.1 \mathrm{sec}$ (Table 1). The correlation between the PPT and heart rate were demonstrated in Fig. 2 . The regression equation relating the variables was $\mathrm{PPT}=5.2-0.018 \times$ (heart rate) $(r=-0.87$, $p<0.001)$. A corrected PPT $(\mathrm{cPPT})$ was obtained by rotation of the above equation as a means of expressing the relationship between the PPT and heart rate $: \mathrm{cPPT}=\mathrm{PPT}+0.018 \times($ heart rate $)-2.1$. The $\mathrm{cPPT}$ averaged $3.2 \pm 0.0 \mathrm{sec}$ (Table 1) ; the mean cPPT was $3.3 \pm 0.1 \mathrm{sec}$ in boys and $2.9 \pm 0.1 \mathrm{sec}$ in girls, and no significant difference was observed between both sexes. The cPPT was constant over the any level of heart rate. A significant positive correlation was found between the cPPT and body surface area $(r=0.41, p<0.05)$ (Fig. 3). Left ventricular ejection fraction, peak ejection rate and peak filling rate averaged $68 \pm$ $2 \%, 4.2 \pm 0.3 / \mathrm{sec}$ and $4.8 \pm 0.3 / \mathrm{sec}$ (Table 1 ). No significant correlation was observed between these three indices and each of heart rate and body surface area (Figs. 4-6). In patients with endocardial fibroelastosis, the cPPT average $4.7 \pm$ $0.4 \mathrm{sec}$ and was significantly higher than that in normal subjects $(p<0.001)$. Left ventricular ejection fraction, peak ejection rate and peak filling rate averaged $28 \pm$ $4 \%, 1.7 \pm 0.2 / \mathrm{sec}$ and $1.8 \pm 0.2 / \mathrm{sec}$. Each value was significantly lower than that in normal subjects $(p<0.001)$ (Table 2 ).

\section{Discussion}

In order to detect the abnormality in cardiac performance of patients with heart diseases, it is necessary to determine normal values for parameters derived 
TABLE 1. Radionuclide angiocardiographic data in normal subjects

\begin{tabular}{|c|c|c|c|c|c|c|c|c|c|}
\hline Case & $\begin{array}{l}\text { Age } \\
\text { (m) }\end{array}$ & Sex & $\begin{array}{l}\mathrm{BSA} \\
\left(\mathrm{m}^{2}\right)\end{array}$ & $\begin{array}{l}\mathrm{HR} \\
(/ \mathrm{min})\end{array}$ & $\begin{array}{l}\text { PPT } \\
(\mathrm{sec})\end{array}$ & $\begin{array}{c}\mathrm{cPPT} \\
(\mathrm{sec})\end{array}$ & $\begin{array}{c}\text { LVEF } \\
(\%)\end{array}$ & $\begin{array}{l}\text { LVPER } \\
(/ \mathrm{sec})\end{array}$ & $\begin{array}{l}\text { LVPFR } \\
(/ \mathrm{sec})\end{array}$ \\
\hline 1 M.A. & 6 & $\mathrm{~F}$ & 0.37 & 167 & 2.5 & 3.4 & 67 & 5.2 & 6.6 \\
\hline 2 M.S. & 7 & $\mathrm{~F}$ & 0.36 & 143 & 2.6 & 3.1 & 71 & 2.8 & 2.4 \\
\hline 3 N.T. & 7 & M & 0.42 & 137 & 2.6 & 3.0 & 72 & 3.0 & 2.9 \\
\hline 4 T.S. & 9 & $\mathrm{M}$ & 0.38 & 111 & 2.8 & 2.7 & 83 & 7.4 & 5.8 \\
\hline 5 N.I. & 12 & M & 0.45 & 111 & 3.2 & 3.1 & 59 & 3.9 & 4.8 \\
\hline 6 J.H. & 13 & M & 0.43 & 167 & 2.4 & 3.3 & 80 & 7.4 & 6.2 \\
\hline 7 T.O. & 15 & M & 0.45 & 94 & 3.8 & 3.4 & 62 & 3.3 & 4.3 \\
\hline 8 S.O. & 17 & M & 0.47 & 130 & 2.7 & 2.9 & 88 & 7.1 & 6.5 \\
\hline 9 T.Y. & 18 & M & 0.50 & 130 & 2.8 & 3.0 & 81 & 6.8 & 6.6 \\
\hline 10 K.S. & 18 & M & 0.49 & 125 & 3.1 & 3.3 & 56 & 3.7 & 4.2 \\
\hline 11 M.A. & 19 & F & 0.53 & 118 & 2.8 & 2.8 & 78 & 2.6 & 2.5 \\
\hline 12 C.K. & 20 & F & 0.51 & 140 & 2.7 & 3.1 & 64 & 4.6 & 7.0 \\
\hline 13 A.G. & 21 & $\mathrm{M}$ & 0.52 & 111 & 3.1 & 3.0 & 86 & 5.5 & 7.3 \\
\hline 14 H.E. & 23 & $\mathrm{M}$ & 0.57 & 120 & 3.0 & 3.1 & 54 & 3.5 & 4.2 \\
\hline 15 K.T. & 23 & M & 0.52 & 111 & 3.0 & 2.9 & 71 & 3.7 & 5.4 \\
\hline 16 K.K. & 23 & M & 0.55 & 111 & 3.4 & 3.3 & 71 & 4.4 & 4.5 \\
\hline 17 K.I. & 24 & M & 0.55 & 100 & 3.5 & 3.2 & 59 & 3.3 & 4.3 \\
\hline 18 S.S. & 27 & $\mathrm{M}$ & 0.54 & 105 & 3.1 & 2.9 & 78 & 3.4 & 5.9 \\
\hline 19 T.K. & 30 & $\mathrm{~F}$ & 0.63 & 143 & 3.1 & 3.6 & 65 & 3.8 & 6.6 \\
\hline 20 H.T. & 31 & $\mathrm{~F}$ & 0.55 & 130 & 2.7 & 2.9 & 51 & 4.2 & 4.3 \\
\hline 21 Y.N. & 39 & $\mathrm{~F}$ & 0.59 & 120 & 3.2 & 3.3 & 53 & 3.2 & 3.4 \\
\hline 22 T.A. & 40 & $\mathrm{M}$ & 0.60 & 136 & 2.9 & 3.2 & 54 & 2.7 & 2.5 \\
\hline 23 T.A. & 53 & $\mathrm{M}$ & 0.74 & 88 & 4.0 & 3.5 & 63 & 2.5 & 3.4 \\
\hline 24 M.T. & 54 & $\mathrm{~F}$ & 0.78 & 95 & 3.7 & 3.3 & 58 & 3.7 & 4.2 \\
\hline 25 T.K. & 70 & $\mathrm{M}$ & 0.68 & 111 & 3.5 & 3.4 & 62 & 3.5 & 4.7 \\
\hline 26 J.S. & 76 & $\mathrm{M}$ & 0.80 & 103 & 3.5 & 3.3 & 71 & 4.2 & 3.4 \\
\hline 27 T.I. & 110 & $\mathrm{~F}$ & 0.98 & 88 & 3.8 & 3.3 & 81 & 4.6 & 3.4 \\
\hline Mean & & & & & 3.1 & 3.2 & 68 & 4.2 & 4.7 \\
\hline \pm S.E. & & & & & 0.1 & 0.0 & 2 & 0.3 & 0.3 \\
\hline
\end{tabular}

cPPT, corrected peak to peak time from the right to the left ventricle; EF, ejection fraction; HR, heart rate ; IV, left ventricle ; PER, peak ejection rate ; PFR, peak filling rate; $\mathrm{PPT}$, peak to peak time from the right to the left ventricle.

from the radionuclide angiocardiography. The circulation time, such as the PPT, is influenced by various factors. Breuel et al. (1977) reported that the PPT obtained by this technique in normal subjects was significantly influenced by the age (children, adults), the site of injection (cubital vein, femoral vein), and the radiopharmaceutical ( ${ }^{99 m} \mathrm{Tc}$-pertechnetate, ${ }^{99 m} \mathrm{Tc}$-labelled human serum albumin). In the present study, the site of injection and radiopharmaceutical were consistent. 


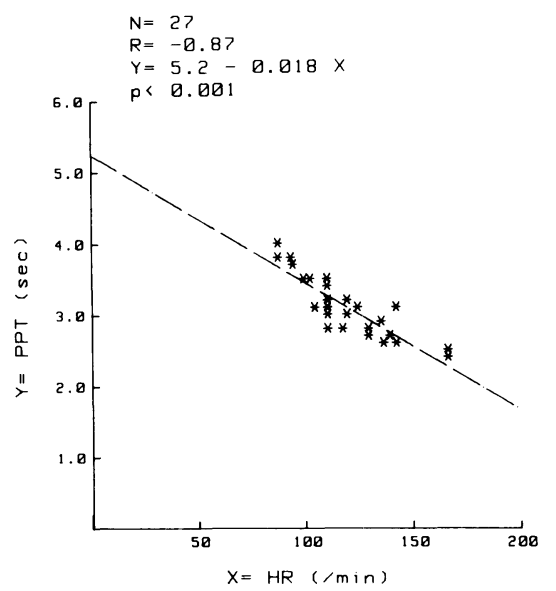

Fig. 2. Correlation of peak to peak time (PPT) with heart rate (HR) in normal subjects.
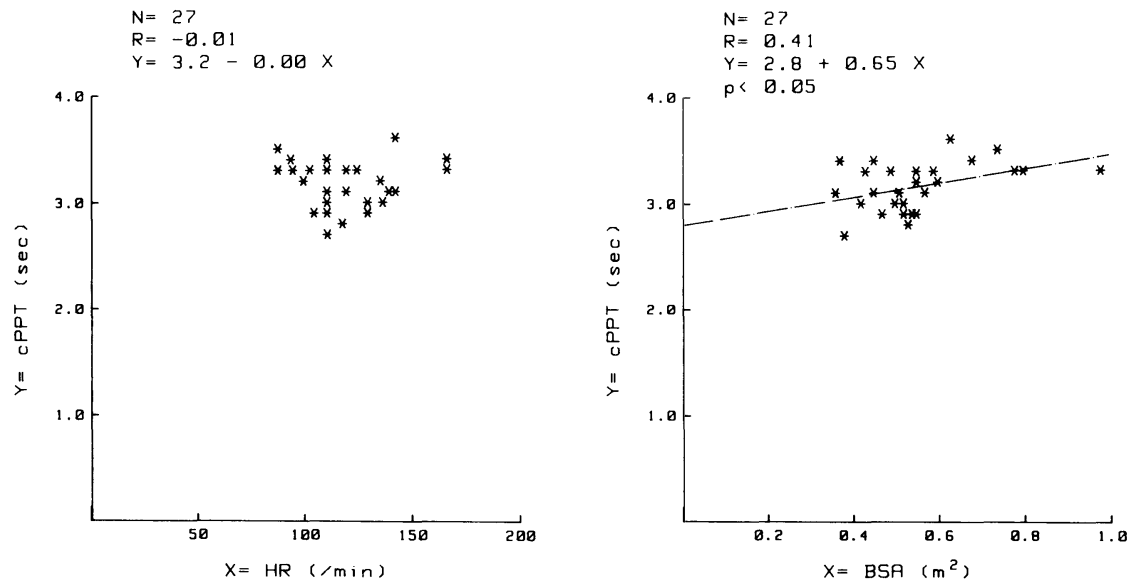

Fig. 3. Corrlation of corrected peak to peak time (cPPT) with heart rate (HR) and body surface area (BSA) in normal subjects.

The PPT was found to be strongly influenced by the heart rate. In order to apply the PPT to patients with heart diseases, the PPT is ideal to be expressed as an index independent of the heart rate. In this study, a PPT corrected by the heart rate (cPPT) was obtained using the regression equation between the PPT and heart rate. Then, the $\mathrm{cPPT}$ was independent of the heart rate. No significant difference between both sexes in values for the cPPT was recognized in our subjects. In order to estimate the influence of the growth in normal subjects on the cPPT, a body surface area was compared with the cPPT. There was a weak but significant positive correlation between them. However, the range of the cPPT was relatively narrow, and so the variation of the body surface area would 
TABLE 2. Radionuclide angiocardiographic data in patients with endocardial fibroelastosis

\begin{tabular}{|c|c|c|c|c|c|c|c|}
\hline & Case & $\begin{array}{l}\text { Age } \\
\text { (m) }\end{array}$ & Sex & $\begin{array}{l}\mathrm{cPPT} \\
\text { (sec) }\end{array}$ & $\begin{array}{c}\text { LVEF } \\
(\%)\end{array}$ & $\begin{array}{c}\text { LVPER } \\
(/ \mathrm{sec})\end{array}$ & $\begin{array}{c}\text { LVPFR } \\
(/ \mathrm{sec})\end{array}$ \\
\hline 1 & $\mathrm{KS}$ & 78 & $\mathrm{~F}$ & 5.6 & 36 & 2.2 & 2.7 \\
\hline 2 & $\mathrm{CY}$ & 68 & $\mathrm{~F}$ & 3.0 & 68 & 2.3 & 2.9 \\
\hline \multirow[t]{4}{*}{3} & YK & 11 & $\mathrm{~F}$ & 3.9 & 27 & 1.5 & 1.3 \\
\hline & & 13 & & 3.5 & 30 & 1.6 & 1.8 \\
\hline & & 26 & & 3.2 & 42 & 1.7 & 1.5 \\
\hline & & 31 & & 3.8 & 46 & 4.2 & 3.7 \\
\hline 4 & SM & 8 & $\mathrm{M}$ & 6.3 & 15 & & \\
\hline \multirow[t]{4}{*}{5} & $\mathrm{RS}$ & 23 & M & 4.4 & 22 & 1.3 & 1.4 \\
\hline & & 24 & & 2.4 & 46 & 1.1 & 1.3 \\
\hline & & 32 & & 3.6 & 40 & 3.1 & 2.5 \\
\hline & & 39 & & 3.8 & 32 & 2.1 & 2.0 \\
\hline 6 & YT & 6 & $\mathrm{M}$ & 5.3 & 22 & 0.8 & 1.0 \\
\hline \multirow[t]{3}{*}{7} & $\mathrm{TW}$ & 13 & $\mathrm{M}$ & 6.8 & 8 & 1.2 & 1.2 \\
\hline & & 15 & & 8.6 & 11 & 0.9 & 1.1 \\
\hline & & 16 & & 5.9 & 7 & 0.9 & 1.1 \\
\hline & $\mathrm{TW}$ & 7 & M & 5.7 & 15 & & \\
\hline & & 11 & & 4.4 & 18 & 1.2 & 1.8 \\
\hline & & 15 & & 4.8 & 24 & 1.5 & 1.5 \\
\hline \multicolumn{3}{|c|}{ Mean } & & 4.7 & 28 & 1.7 & 1.8 \\
\hline \multicolumn{2}{|c|}{ \pm S.E. } & & & 0.4 & 2 & 0.2 & 0.2 \\
\hline
\end{tabular}

cPPT, corrected peak to peak time from the right to the left ventricle; EF, ejection fraction; LV, left ventricle; PER, peak ejection rate; PFR, peak filling rate.
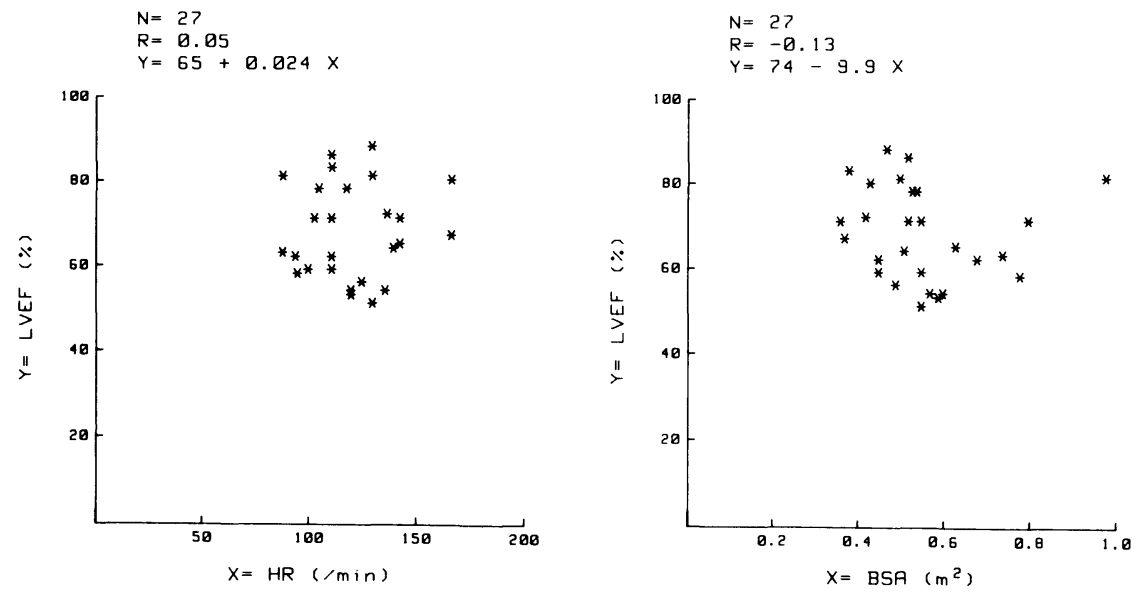

Fig. 4. Correlation of left ventricular ejection fraction (LVEF) with heart rate $(\mathrm{HR})$ and body surface area (BSA) in normal subjects. 

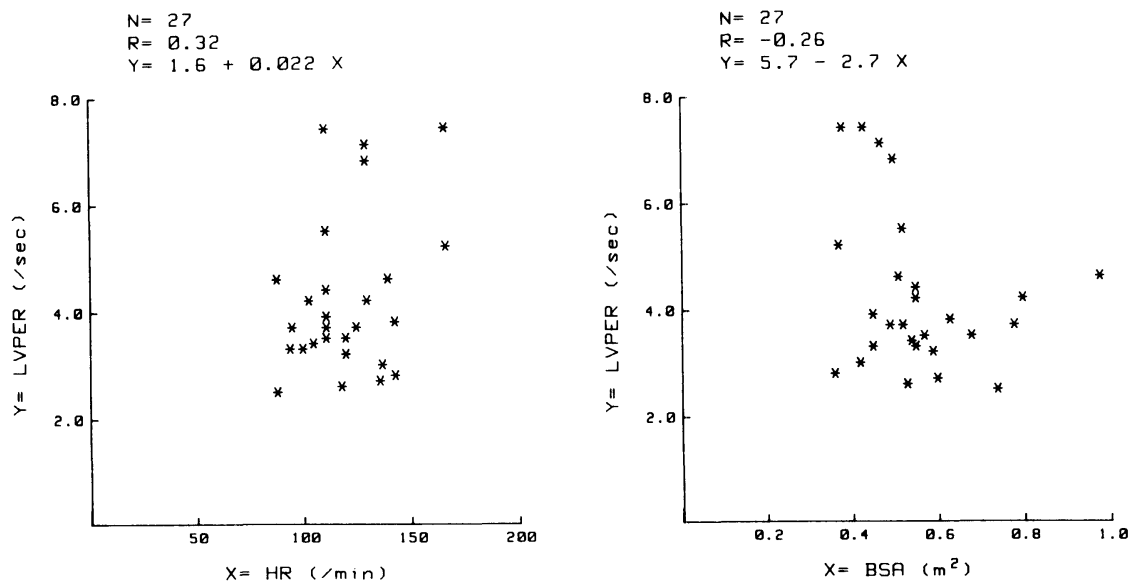

Fig. 5. Correlation of left ventricular peak ejection rate (LVPER) with heart rate (HR) and body surface area (BSA) in normal subjects.
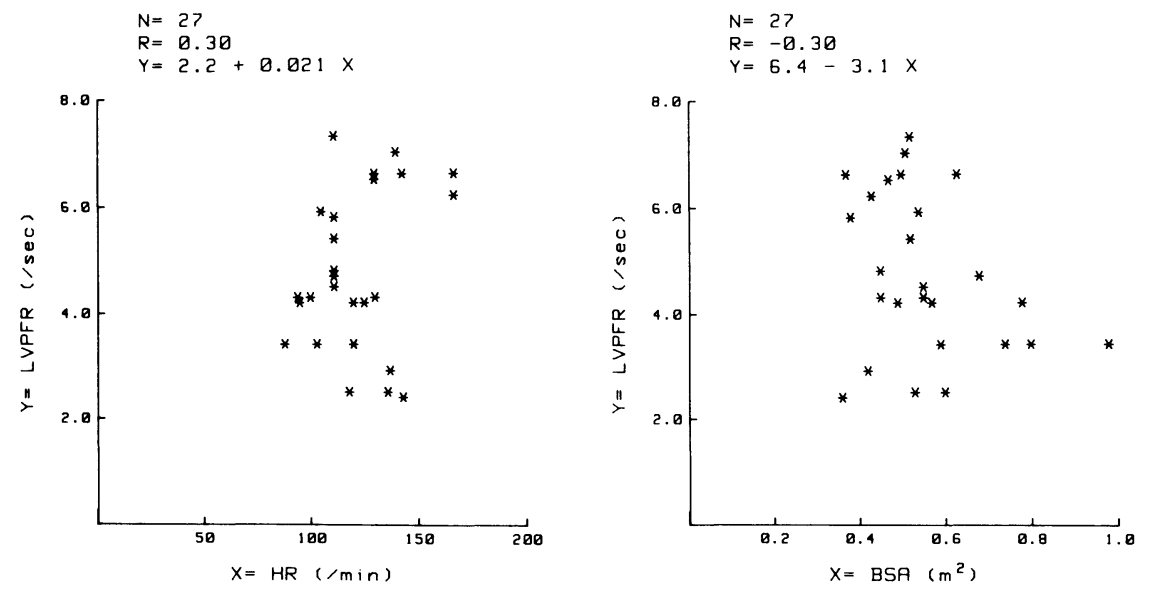

Fig. 6. Correlation of left ventricular peak filling rate (LVPFR) with heart rate $(\mathrm{HR})$ and body surface area (BSA) in normal subjects.

not have to be borne in mind in using the cPPT for pediatric age patients.

An ejection fraction have been utilized as useful index of systolic function. A previous report from this laboratory (Akiba et al. 1983) showed that the ejection fraction obtained by the radionuclide angiocardiography correlated well with that derived from the contrast angiocardiographic technique. In the pesent study, the ejection fraction obtained by the radionuclide angiocardiography was independent of the heart rate and body surface area.

Slutsky et al. (1983) reported that a peak ejection rate obtained from the radionuclide angiocardiography behaved in a fashion similar to the ejection fraction, and was, by itself, neither more useful nor discriminating than the 
ejection fraction alone. Magorien et al. (1984) reported that there was a strong correlation between the peak ejection rate and ejection fraction. In addition, they observed that a peak filling rate determined from the radionuclide angiographic volume curve correlated well with measured hemodynamic variables: maximum negative $\mathrm{dP} / \mathrm{dt}$, time constant and end-diastolic pressure in the left ventricle. These two parameters have been widely accepted for evaluating systolic or diastolic function in adult patients with coronary artery disease, valvular disease or cardiomyopathy. However, these parameters have not been applied to pediatric subjects. Since there was a considerably large individual variation among the normal values of the peak ejection rate and peak filling rate in our data, the diagnostic value of these two parameters may be limited.

Endocardial fibroelastosis is characterized by the fibroelastic tissue over the endocardium, and each or both of the left ventricle and left atrium are involved. This has been clinically divided into the more common type associated with left ventricular dilatation and a rare "contracted type". In the former, left ventricular end-diastolic and end-systolic volumes are greatly increased and the ejection fraction is decreased (Adams and Emmanouilides 1983). All of our cases had dilatated left ventricles. The mean value of the cPPT in patients with endocardial fibroelastosis were higher than that in normal subjects. Breuel et al. (1977) reported that the circulation time was directly related to the end-diastolic volume of the left ventricle. In our study, also, prolonged cPPT may be attributed to an enlargement of the left ventricle. All of the left ventricular ejection fraction, peak ejection rate and peak filling rate in the present study were lower than those in normal subjects. We previously stated the limitation of clinical application of the peak ejection rate and peak filling rate because of their wide variation in normal values. However, the abnormality of these parameters in our patients with endocardial fibroelastosis can be detected. These findings suggest that the left ventricular systolic and diastolic functions were disturbed. In conclusion, the radionuclide angiocardiography is an useful tool for monitoring cardiac performance and deciding medical management of patients with endocardial fibroelastosis.

\section{Acknowledgments}

We gratefully acknowledge Prof. Tadashi Hayashi for his advice and criticism in preparing this manuscript.

\section{References}

1) Adams, F.H. \& Emmanouilides, G.C. (1983) Moss' Heart Disease in Infants, Children, and Adolescents. 3rd ed., Williams•\& Wilkins, Baltimore.

2) Akiba, T., Ishihara, T., Yoshikawa, M., Sato, T. \& Komatani, A. (1983) Calculation of right and left ventricular ejection fraction in infants and children by first pass radionuclide angiocardiography using self-synchronization method. Tohoku J. exp. Med., 140, 413-419. 
3) Breuel, H., Emrich, D., Vivie, R., Heimburg, P., Luig, H. \& Kisselbach, V.J. (1977) Quantitative nuclear angiocardiography in valvular heart disease. Europ. J. Cardiol., 6/4, 271-283.

4) Haycock, G.B., Chir, B., Schwartz, G.J. \& Wisotsky, D.H. (1978) Geometric method for measuring body surface area: A height-weight formula validated in infants, children, and adults. J. Pediatr., 93, 62-66.

5) Komatani, A., Takamiya, M., Takahashi, K. \& Yamaguchi, K. (1981) Radio nuclide cardiac examination with "self-synchronization"-The new method without ECG gating-. Jap. J. nucl. Med., 18, 315-321. (in Japanese with English abstract)

6) Magorien, D.J., Shaffer, P., Bush, C., Magorien, R.D., Kolibash, A.J., Unverferth, D.V. \& Bashore, T.M. (1984) Hemodynamic correlates for timing intervals, ejection rate and filling rate derived from the radionuclide angiographic volume curve. Amer. $J$. Cardiol., 53, 567-571.

7) Slutsky, R.A., Mancini, G.B.L., Gerber, L.H., Dittrich, H.C. \& Higgins, C.B. (1983) Analysis of ventricular emptying and filling indexes during increases in arterial pressure. Amer. J. Cardiol., 51, 468-475. 